\title{
The influence of a moderate aerobics programme on the body self-image of women in middle adulthood
}

\author{
Andrea K Daniels (MA (Psychology)) \\ Rudolph L van Niekerk (D Lit et Phil (Psychology)) \\ Department of Psychology, University of Johannesburg \\ Correspondence to: Leon van Niekerk (leonvn@uj.ac.za)
}

\begin{abstract}
Objectives. This empirical study investigated the effect of a moderate aerobic exercise programme on the body self-image of a sample of women $(n=49)$ in middle adulthood with a mean age of 54.2 years.

Methods. The participants were randomly assigned to an experimental group $(n=24)$ and a control group $(n=25)$. The experimental group participated in a (guided) moderate aerobics programme over six weeks, while the control group participated in a sedentary (guided) meditation programme. The participants in both groups were assessed for body self-image using the nine factors defined in the Body Self-Image Questionnaire (BSIQ) of Rowe (2000). The BSIQ comprises both perceptual-cognitive and affective-attitudinal factors.

Results. The results indicated that there was an overall positive shift in the perceptual-cognitive factors of the body self-image in the exercise group, namely for overall appearance evaluation, health fitness evaluation and fatness evaluation. Although no significant shifts were found in all the affective-attitudinal factors of the participants, there was a significant change in the negative affect of the participants.

Conclusion. The results suggest that such a programme has a positive influence on the way these women think and feel about their bodies. No significant changes were found in the body selfimage of the control group. These findings suggest the positive effect of a (guided) aerobic exercise programme in improving the body self-image of women in middle adulthood.
\end{abstract}

\section{Introduction}

Body self-image is a psychological construct which has gained increasing attention in current years, and researchers ${ }^{1,2}$ reported that active groups have a better concept of their bodies and body image than sedentary groups. With the extensive growth of the media and technology into almost every aspect of our lives, the human body is portrayed, photographed, pictured and ultimately adored or abhorred more than ever, resulting in increasing statistics of body dysmorphia and obsessions with appearance, weight, fitness and health. ${ }^{1}$ The primary questions posited in this research study were: what happens to the body self-image when women exercise, specifically in terms of the cognitive, perceptual, affective and attitudinal aspects of their body self-image.

\section{Relationship between exercise and self-image}

A growing number of controlled studies have identified the positive effects of exercise on general psychological well-being in ageing women. ${ }^{3,4}$ In a wide-ranging literature review, McAuley ${ }^{5}$ has considered the relation between exercise and both positive and negative psychological health. In line with other review articles, McAuley ${ }^{5}$ reported a positive relationship between exercise and self-esteem, self-efficacy, psychological well-being, and cognitive functioning, and a negative relationship between exercise and anxiety, stress, and depression. Such studies reinforce the notion that exercise has significant psychological health benefits for people who exercise regularly. The psychological benefits of exercise extend to positive changes in body self-image for women that occurred following exercise interventions. ${ }^{1,6,7}$ Such changes can be due to physiological processes in which exercise increases concentrations of the brain's neurotransmitters by stimulating the sympathetic nervous system. ${ }^{8}$ Further research has shown that exercise is one of the most effective means of improving body self-image. ${ }^{9,10}$

There is widespread support for a positive and lasting relationship between participation in regular exercise and various indices of mental health, and several consensus documents and reviews have been published in this field. ${ }^{11,12}$ The evidence for psychological benefits, although impressive for mentally healthy individuals, is even stronger for psychiatric populations. ${ }^{13}$ A number of studies have demonstrated a positive relationship between exercise and mental health in alcoholics, ${ }_{14}^{14}$ people with schizophrenia ${ }^{15}$ and those with clinical depression. ${ }^{16}$

Despite the growing body of evidence supporting the relationship between exercise and mental health, organisations have been reluctant to endorse the use of exercise in treating mental illness. Furthermore, exercise has not been widely adopted by clinical psychologists and psychiatrists as a viable adjunctive intervention strategy for improving the mental health of patients. A recent overview of depression and its treatment in the UK, for example, made no mention of the value of exercise. ${ }^{17}$ Similarly, Biddle et al. ${ }^{11}$ reported that exercise as an intervention was not considered appropriate or of any incidental value by clinical psychologists. It appears that much work has to be done to convince those who deliver mental health services to focus on the relationship between mind and body and to look more positively at the role of exercise as a treatment in mental health issues. ${ }^{16}$ This paper therefore explores the potential value of exercise as an adjunctive treatment in improving body self-image in a 'healthy' population of women in middle adulthood, who have their own and unique challenges.

Challenges confronting women in middle adulthood The developmental stage of middle adulthood occurs between the ages of 40 and $65 .{ }^{18,19}$ Women in middle adulthood are confronted with many psychological changes, ${ }^{20}$ midlife transitions, ${ }^{19}$ and 
physiological changes associated with signs of ageing, ${ }^{21}$ resulting in a loss of muscle mass, muscle strength and muscle fibres. ${ }^{22}$ Women in middle adulthood are therefore at risk of internalising negative mental representations of their body self-image. Mciza ${ }^{23}$ found that differences in body image among South African women are highly driven by cultural norms, urbanisation and socio-economic status. Many South African women, because of societal pressures, are at risk of suffering from a loss of self-esteem. ${ }^{24}$ South Africa, in its current climate of socio-economic emergence and transformation, engenders many challenges and stressors upon its divergent population. These stressors are seen to impact most severely on women and children. According to Pillay and $\mathrm{Kriel}^{25}$ who conducted a study on South African women seeking psychological interventions, over one-third had relationship problems, $21 \%$ had depression, and $14 \%$ presented with suicidal behaviour. Furthermore, nearly half the women reported significant financial problems. Of the 174 married (or cohabiting) women, 95\% experienced relationship problems, $57 \%$ reported substance-abusing partners, and $48 \%$ reported violent partners. Clinician estimates revealed notably low self-esteem in $65 \%$ of the women. Not least susceptible to these stressors are South African women in the stage of middle adulthood who, in a persistently patriarchal climate, form a group that is both largely underrepresented and unsupported, with minimal access to resources such as health facilities, support groups and psychological interventions.

\section{Methods}

The specific objectives of this study were to determine if a professionally guided, moderate aerobics programme would have an impact on the body self-image of a group of sedentary South African women in the phase of middle adulthood. Forthcoming from this aim, the following research questions were constructed:

- How does a moderate aerobics programme (of movement) change the body self-image of women in middle adulthood?

- How does a (sedentary) programme of guided meditation change the body self-image of women in middle adulthood?

- Does a moderate aerobics programme change the body image of sedentary women in the phase of middle adulthood more than a programme of sedentary guided meditation?

This study therefore aimed to examine the body self-image constructs with a pre-test post-test experimental design with a control group. A programme of (guided) moderate aerobics was applied to the experimental group $(n=24)$, while a programme of sedentary guided meditation was applied to a control group $(n=25)$ on a sample of $49(n=49)$ women in the phase of middle adulthood. The participants in both groups were assessed for body selfimage using the nine sub-scales defined in the Body Self-Image Questionnaire $(\mathrm{BSIQ}){ }^{26}$ The $\mathrm{BSIQ}$ comprises both perceptualcognitive and affective-attitudinal items, which are intended to elicit responses pertaining to these different constructs. Moderate to high internal consistency (Cronbach's alpha) was found on all the subscales, ranging from 0.59 to 0.90 .

\section{Instruments}

The constructs of body self-image were measured using the 51 -item $\mathrm{BSIQ}{ }^{26}$ The BSIQ is a self-administered questionnaire, with questions that elicit answers on a 5-point Likert scale, with 1 (not at all true of myself) to 5 (completely true of myself). Apart from reversescored items, the higher the score, the more positive the evaluations and perceptions of body self-image.

The BSIQ is currently the most widely used measure of global body self-image within health psychology. It has received extensive psychometric scrutiny (i.e. confirmatory factor analysis) and has been validated on several samples of normal and divergent groups, including individuals with eating disorders and body dimorphic disturbances. ${ }^{26}$ Furthermore, the BSIQ has been proven to be a reliable, valid measure and has shown an internal consistency of $0.87 .^{9}$ Internal consistency (Cronbach's alpha) for the nine subscales have ranged from $\alpha=0.78$ (social dependence) to 0.94 (fatness evaluation). ${ }^{26}$

The cognitive-perceptual constructs of body self-image is conceptualised and measured in the $\mathrm{BSIQ}^{26}$ on the following subscales:

- Overall appearance evaluation. This factor includes self representations such as 'I perceive my overall appearance to be ugly/ fat/scruffy etc.', based on objective self-evaluations such as one's attire, grooming, actual weight, and may extend as far as 'I perceive this because I can no longer fit into my jeans'.

- Fatness evaluation. This dimension of body self-image would produce statements such as 'My buttocks are fat!' Again, this factor is based on objective self-evaluations of fatness which the individual perceives as a consequence of weighing more, of not being able to fit into one's jeans.

- Health fitness evaluation. This dimension of body self-image would produce statements such as 'I feel fit and healthy!' Again, this factor is based on objective self-evaluations of fitness and health which the individual perceives as a consequence of working out more frequently, eating better, etc.

The affective-attitudinal constructs of body self-image is conceptualised and measured in the following sub-scales:

- Health fitness influence. This factor includes self-representations such as 'I feel that my fitness levels impact on my selfconfidence and well-being', based on subjective feelings and attitudes.

- Attention to grooming. This factor of body self-image would produce statements such as 'I like to be seen in smart clothes', which represents the individuals' attitudes and feelings about their presentation to others.

- Negative affect. This factor of body self-image would produce statements such as 'I feel ashamed and depressed about my weight'. Again, this factor is based on subjective attitudes and feelings.

- Investment in ideals. This factor of body self-image would produce statements such as 'I like people to think I am a kind person'. Again, this factor is based on subjective attitudes and feelings.

- Height dissatisfaction. This factor of body self-image would produce statements such as 'I think I am too short'. Again, this factor is based on subjective attitudes and feelings.

\section{Sample}

Sixty $(n=60)$ normal weight (ascertained by means of body mass index (BMI)), sedentary females in middle adulthood (between the ages of 45 and 60 ), with no history of low-impact aerobic exercise, were asked to volunteer for participation in the study. Invitations to participate were given at various women support groups and training centres in the local community by word of mouth. Inclusion criteria were ascertained through the use of a biographical questionnaire and a physical attributes questionnaire. After the exclusion of women who did not meet the inclusion criteria, a sample of 49 women was obtained and randomly assigned to the experiment $(n=24)$ and control $(n=25)$ groups. A total of nine participants had to exit from the study due to work constraints, travel arrangements and family responsibility. The mean age of the total sample was $(54.2 \pm 6.98)$ years, with the mean age of $(53.6 \pm 7.28)$ for the experiment group and $(55.9 \pm 6.79)$ for the control group. 
Table I. Physical attributes of the sample

\begin{tabular}{|c|c|c|c|c|c|}
\hline \multicolumn{2}{|c|}{ Body mass index } & \multicolumn{2}{|c|}{ Body fat (\%) } & \multicolumn{2}{|c|}{ Fitness } \\
\hline Scale & Participants & Scale & Participants & Scale & Participants \\
\hline $18.5-24.9$ & $\mathrm{~N}=40$ & Slim & $N=31$ & $61-75(A)$ & $\mathrm{N}=60$ \\
\hline (normal) & $68 \%$ & & $51 \%$ & & $100 \%$ \\
\hline $25-29.9$ & $N=20$ & Normal & $N=29$ & $76-86$ (AA) & 0 \\
\hline (overweight) & $32 \%$ & & $49 \%$ & & \\
\hline $\begin{array}{c}30 \& \text { above } \\
\text { (obese) }\end{array}$ & 0 & Obese & 0 & & \\
\hline
\end{tabular}

\section{Research design and intervention}

Participants were randomly assigned to one of two 6-week programmes. This study utilised a two-group pre-test post-test experimental design where a moderate aerobics programme was administered with the experimental group, while the control group was assigned a meditation programme, rather than being told to do nothing, as a way to control for possible social interaction effects during exercise. ${ }^{27}$ Randomisation was stratified by BMI to ensure balanced weight distribution of the women in each group and internal validity of the study. Data analysis (descriptive statistics and independent sample $t$-tests) was done to determine the extent to which the separate interventions influenced body self-image in the two groups.

The experimental group participated in bi-weekly exercise session lasting for 45 minutes per session. After an adequate warmup session of 10 minutes, which included breathing, focused body work, upper body arm exercises and light cardio-exercises (such as walking forwards and backwards, lunges, stretches and knee lifts), the aerobics session started. The session lasted for 35 minutes and included exercises such as the grapevine step, marching, knee lifts, walking routines, the v-step and hamstring curls. These exercises engaged the major muscle groups and body areas where the participants expressed both fatness and fitness concerns. Exercises began at approximately $40 \%$ of $\mathrm{Vo}_{2 \mathrm{max}}$ for 15 minutes and gradually increased to approximately $60-70 \%$ of $\mathrm{Vo}_{2 \max }$ for the remaining 25 minutes. Polar heart rate monitors were used to ensure that participants did not exceed $70 \%$ of $\mathrm{Vo}_{2}$ max. The control group engaged in a bi-weekly (sedentary) guided meditation programmes for 45 minutes per session. Each session comprised a 10-minute introduction and discussion session, followed by a 5-minute chanting and relaxation session and a 20-minute meditation session. The session was concluded with 5 minutes of breathing and 5 minutes of discussion.

\section{Results}

The results presented in Table I indicate that all participants were within the acceptable ranges of $\mathrm{BMI}$, showing $40(68 \%)$ participants being within normal range, and $20(32 \%)$ being overweight. Fatness percentage levels showed 31 (51\%) participants with a slim body fat percentage and $29(49 \%)$ within the normal range of body fat percentage. These anthropomorphic results indicated that all participants were fit enough to participate safely in the programme of moderate aerobic exercise.

The results of the pre-tests and post-tests on the sub-scales of the BSIQ are presented in Table II. As the study was more concerned with within-group changes rather than with between-group differences, only within-group change results are presented. Even though the aerobics and meditation programmes could have had similar effects on the cognitive-perceptual and affective-attitudinal sub-scales of the BSIQ, the validity of the study would not be compromised. The mean scores, standard deviations and significance of the within changes (set at $p<0.01$ ) for the experiment and control groups on the cognitive-perceptual sub-scales and affective-attitudinal sub-scales are indicated.

The results presented in Table II indicate a significant difference in overall appearance evaluation $(p=0.001)$. Thompson et al. ${ }^{28}$ also reported enhanced scores on the physical appearance state among women with low appearance evaluation in their research. The results (Table II) further indicated a significant difference in the health fitness evaluation $(p=0.001)$ and fatness evaluation $(p=0.001)$ of the experimental group. Regular activity and improved fitness have a beneficial effect on self-esteem and body image. ${ }^{10}$ Cash and Pruzinsky ${ }^{29}$ reported a significant correlation between appearance evaluation and fitness orientation (0.542) as well as between appearance evaluation and health orientation (0.533). Their findings indicated that participants who were generally more positive about their appearance place a greater importance on fitness and health. However, they also warned that these individuals may have a greater chance of suffering from body-image disturbance. These significant differences were not achieved in the control group, indicating that the 6-week moderate aerobics programme had a significant positive impact on the cognitive-perceptual aspects of the body self-image of the participants.

There were no significant changes in all but one of the affective-attitudinal sub-scales. Investment in ideals, factor health fitness influence (HFI), attention to grooming (AG) or height dissatisfaction (HD) had significance levels larger than $p=0.01$. However, for negative affect (NA) there was a significant positive shift in the participant's affect for both the experimental $(p=0.001)$ and control group $(p=0.002)$. These findings are in agreement with Russo-Neustadt et al., ${ }^{8}$ who maintained that exercise increases concentrations of the brain's neurotransmitters by stimulating the sympathetic nervous system. They maintain that since exercise increases brainderived neurotrophic factor (BDNF) production directly, there is a reinforcement of the serotonin-BDNF loop, indicating exercise's significant potential as a mood enhancer.

These results showed significantly improved body self-image scores for the experimental group who did 6-week moderate aerobic exercise. The experimental group experienced the greatest improvement in body self-image, specifically in the domain of perceptual-cognitive body self-image (overall appearance evaluation, health-fitness evaluation, and fatness evaluation). It seems therefore that a programme of exercise (movement) is significantly more beneficial to body self-image than a programmeme of sedentary guided meditation. 
Table II. Within-group changes for both the experimental and control groups

\begin{tabular}{|c|c|c|c|c|c|c|}
\hline \multirow[b]{2}{*}{ Scale } & \multirow[b]{2}{*}{ Group } & \multicolumn{2}{|l|}{ Pre-test } & \multicolumn{2}{|l|}{ Pre-test } & \multirow[b]{2}{*}{$p$-value } \\
\hline & & Mean $\pm S D$ & SEM & Mean $\pm S D$ & SEM & \\
\hline \multicolumn{7}{|l|}{ Cognitive-perceptual sub-scales } \\
\hline \multirow[t]{2}{*}{ Overall appearance evaluation (OAE) } & Experiment & $2.69 \pm 0.363$ & 0.074 & $3.39 \pm 0.499$ & 0.102 & 0.001 \\
\hline & Control & $2.72 \pm 0.498$ & 0.104 & $3.04 \pm 0.517$ & 0.108 & 0.023 \\
\hline \multirow[t]{2}{*}{ Health fitness evaluation (HFE) } & Experiment & $2.39 \pm 0.302$ & 0.062 & $3.27 \pm 0.617$ & 0.126 & 0.001 \\
\hline & Control & $2.70 \pm .439$ & 0.091 & $2.84 \pm .451$ & 0.094 & 0.019 \\
\hline \multirow[t]{2}{*}{ Fatness evaluation (FE) } & Experiment & $3.27 \pm 0.366$ & 0.075 & $2.56 \pm 0.385$ & 0.079 & 0.001 \\
\hline & Control & $3.12 \pm 0.388$ & 0.081 & $3.06 \pm 0.414$ & 0.086 & 0.302 \\
\hline \multicolumn{7}{|l|}{ Affective-attitudinal sub-scales } \\
\hline \multirow[t]{2}{*}{ Investment in ideals (II) } & Experiment & $3.39 \pm 0.373$ & 0.076 & $3.34 \pm 0.487$ & 0.099 & 0.095 \\
\hline & Control & $3.26 \pm 0.384$ & 0.080 & $3.20 \pm 0.327$ & 0.068 & 0.317 \\
\hline \multirow[t]{2}{*}{ Health fitness influence (HFI) } & Experiment & $3.53 \pm 0.321$ & 0.066 & $3.59 \pm 0.431$ & 0.088 & 0.370 \\
\hline & Control & $3.39 \pm 0.424$ & 0.088 & $3.43 \pm 0.428$ & 0.089 & 0.212 \\
\hline \multirow[t]{2}{*}{ Negative affect (NA) } & Experiment & $2.90 \pm 0.368$ & 0.075 & $2.26 \pm 0.357$ & 0.073 & 0.001 \\
\hline & Control & $2.89 \pm 0.579$ & 0.125 & $2.57 \pm 0.490$ & 0.102 & 0.002 \\
\hline \multirow[t]{2}{*}{ Attention to grooming (AG) } & Experiment & $3.25 \pm 0.489$ & 0.100 & $3.31 \pm 0.450$ & 0.092 & 0.347 \\
\hline & Control & $3.39 \pm 0.482$ & 0.100 & $3.50 \pm 0.452$ & 0.094 & 0.059 \\
\hline \multirow[t]{2}{*}{ Height dissatisfaction (HD) } & Experiment & $1.74 \pm 0.511$ & 0.104 & $1.71 \pm 0.409$ & 0.083 & 0.516 \\
\hline & Control & $2.32 \pm 0.788$ & 0.164 & $2.22 \pm 0.769$ & 0.160 & 0.038 \\
\hline
\end{tabular}

\section{Discussion}

That body self-image (on a cognitive-perceptual level) improved significantly in the exercise group. This finding supports the original research questions and is consistent with research supporting the positive outcomes of a programme of moderate aerobics with women in the phase of middle adulthood. Apart from negative affect, there were no significant differences in either of the sub-scales of body self-image in the control group that did a programme of sedentary guided meditation.

These findings therefore suggest a positive influence of (guided) moderate aerobics exercise on improved body selfimage. In agreement with this, various researchers ${ }^{10,30,31}$ showed that active adults had a more positive body-image than inactive adults. It seems therefore that participation in physical activity can increase physical abilities and fitness and this, in turn, results in self-esteem improvement and positive attitude towards your body. Sonstroem and Morgan's ${ }^{32}$ self-esteem model (EXEM) proposed that the objective evaluation from physical capabilities may be increased by exercise. This evaluation can improve self-acceptance or self-worth without considering perceived competency.

Fox and Corbin $^{33}$ in the development of the Physical Self-Perception Profile (PSPP) showed that there are strong associations between efficacy and physical fitness. Sonstroem et al. ${ }^{34}$ also proposed that self-esteem improvement following participation in physical activity can be attributed to physical fitness improvement, meeting one's personal goals, competency improvement, health behaviour promotion such as sufficient sleep and nutrition and confront with new social experiences as a result of activity with others.
The results of this study were in agreement with other previous findings and can be applied to women in middle adulthood. Tucker and Maxwell, ${ }^{35}$ for example, found the body cathexis scores of females participating in moderate exercise to be greater than those of a control group. Results of the current study lend support to these findings in that the aerobic group had significantly better positive body image scores in several of the body image subscales than those in the control group. In light of the positive effect of an exercise programme on body self-image changes as opposed to that of one which is meditative and predominantly intrinsically focused, physical activity should gain more credibility as a body self-image enhancing technique. As clinical psychologists are inclined to dismiss physical activity as a possible treatment ${ }^{11}$ of body self-image issues, this research provides evidence to suggest that an approach that excludes physical exercise as part of an intervention could be questioned.

\section{Conclusion}

Empowering people and the communities in which they live is an important aim of exercise psychology, and this exploration adds a dynamic component to ongoing dialogue within the field of exercise psychology and women within our society. A healthy body self-image is therefore clearly a prerequisite for overall positive self-regard, especially for women in the phase of middle adulthood. In this regard, this research study can be seen to be beneficial to both healthy and disordered sectors of society.

Further research is needed to define how the psycho-dynamic properties of (guided) exercise and exercise therapy can be utilised effectively as a tool for the treatment of a variety of psychophysiological disorders and disabilities, including psychotherapeutic, psycho-social, and physical rehabilitation. 


\section{REFERENCES}

1. Cash TF. Body image attitudes: Evaluation, investment and affect. Perceptual and Motor skills 1994;78:1168-1170.

2. Shaw SM. Body image among adolescent women: the role of sports and physical active leisure. Journal of Applied Recreation Research 1994:16(4):349-367.

3. Netz Y, Wu MJ, Becker BJ, Tennenbaum G. Physical activity and psychological well-being in advanced age: a meta-analysis of intervention studies. Psychol Aging 2005;20:272-284.

4. Viera PN, Mata J, Silva MN, et al. Predictors of psychological well-being during behavioral obesity treatment in women. Journal of Obesity 2011:18. doi:10.1155/2011/936153

5. McAuley E. The role of efficacy cognitions in the prediction of exercise behavior. Womens Health Issues 2003;13(4):158-166.

6. Finkenberg ME, DiNucci J, McCune SL, Chenette T, McCoy P. Commitment to physical activity and anxiety about physique among college women. Perceptual and Motor Skills 1998;87:1393-1394.

7. Henry R, Anshel M, Michael T. Effects of aerobic and circuit training on fitness and body image among women. Journal of Sport Behavior 2006;29(4):281-304

8. Russo-Neustadt AA, Beard RC, Huang YM, Cotman CW. Physical activity and antidepressant treatment potentiate the expression of specific brainderived neurotrophic factor transcripts in the rat hippocampus. Neuroscience 2000;101(2):305-312.

9. Baldwin MK, Courneya KS. Exercise and self-esteem in breast cancer survivors: An application of the exercise and self-esteem model. Journal of Sport and Exercise Psychology 1997;19:347-358.

10. Davis C. Body Image, Exercise and Eating Behaviors: The Physical Self from Motivation to Well-being. Champaign: Human Kinetics, 1997:143174

11. Biddle SJH, Fox K, Boutcher SH. The way forward for physical activity and the promotion of psychological well-being. In: Biddle SJH, Fox K, Boutche $\mathrm{SH}$, eds. Physical Activity and Psychological Well-being. London: Routledge, 2000:154-168.

12. Craft LL, Landers DM. The effects of exercise on clinical depression and depression resulting from mental illness: A meta-analysis. Journal of Sport \& Exercise Psychology 1998;20:339-357.

13. Biddle SJH, Mutrie N. Psychology of Physical Activity: Determinants, WellBeing and Interventions. London: Routledge, 2003:236-254.

14. Donaghy ME. An investigation into the effects of exercise as an adjunct to the treatment and rehabilitation of the problem drinker. $\mathrm{PhD}$ thesis, Medical Faculty, Glasgow University, Glasgow, 1997.

15. Chamove A. Positive short-term effects of activity on behaviour in chronic schizophrenic patients. Br J Clin Psychol 1986;25:125-133.

16. Mutrie $\mathrm{N}$. The relationship between physical activity and clinically defined depression. In: Biddle SJH, Fox K, Boutcher SH, eds. Physical Activity and Psychological Well-being. London: Routledge, 2000:46-62

17. Hale AS. ABC of mental health: Depression. J Sports Sci 1997:315:43.

18. Lachman M. Handbook of Midlife Development. New York: Wiley, 2001.
19. Levinson D. The midlife-transition: a period of adult psychosocial development. Psychiatry 1977;40:99-112.

20. Mroczek DK, Spiro A, Griffen PW, Neuperd S. Social influences on adult personality, self-regulation and health. In: Schaie KW, Carstensen L, eds. Social Structures, Aging and Self-Regulation. New York: Springer, 2006:69-83.

21. Baron, RA, Byrne D. Social Psychology: Understanding Human Interaction. Boston: Allyn and Bacon,1991.

22. Hakkinen K. Neuromuscular adaptation during strength training, aging, detraining and immobilization. Critical Reviews in Physical Rehab Medicine 1994;6:161-198.

23. Mciza Z. Development and validation of instruments measuring body image and body weight dissatisfaction in South African mothers and their daughters. Nutrition 2005;21:34-50.

24. Alipoor SA, Moazami-Goodarzi M, Zarra-Nezhad, Zaheri L. Analysis of the relationship between eating attitudes and body shape in female students. J Appl Sci 2009;10:1994-1997.

25. Pillay AL, Kriel AJ. Mental health problems in women attending district-level services in South Africa. Journal of Social Science Med 2006;63(3):587592.

26. Rowe DA, Benson J, Baumgartner T. Development of the Body Self-Image Questionnaire. Measurement in Physical Education and Exercise Science 1999;3(4):223-247.

27. Portney L, Watkins M. Foundations of Clinical Research: Applications to Practice. New Jersey: Prentice Hall, 2008.

28. Thompson JK, Coovert MD, Stormer SM. Body image, social comparison, and eating disturbance: A covariance structure modelling investigation. In J Eat Disord 1999; 6:43-51.

29. Cash TF, Pruzinsky T. Body Image: A Handbook of Theory, Research, and Clinical Practice. New York: Guilford, 2002.

30. Franzoi SL. Effects of aerobic exercise on female body esteem: A multidimensional approach. Paper presented at the Annual Convention of the American Psychology, 22 - 26 August 1986. Washington DC (web SPIRS Search ED 282115).

31. Daley AJ, Parfitt G. Physical self-perceptions, aerobic capacity and physical activity in male and female members of a corporate health and fitness club. Perceptual and Motor Skills 1996;83:1075-1082.

32. Sonstroem RJ, Morgan WP. Exercise and self-esteem: Rationale and model. Medicine and Science in Sports and Exercise 1989;21:329-337.

33. Fox KR, Corbin CB. The physical self-perception profile: Development and preliminary validation. Journal of Sport and Exercise Psychology 1989;11:408-430.

34. Sonstroem RJ, Harlow LL, Josephs L. Exercise and self-esteem: Validity of model expansion and exercise associations. Journal of Sport and Exercise Psychology 1994;16: 29-42.

35. Tucker LA, Maxwell K. Effects of weight training on the emotional well-being and body image of females: predictors of the greatest benefit. American Journal of Health Promotion 1992;6:338-344. 